\title{
A delayed effect of ozone fumigation on photosynthesis of Norway spruce
}

\author{
D. Eamus ${ }^{1}$, J.D. Barnes², L. Mortensen ${ }^{3}$, H. Ro-Poulsen 4 and \\ A.W. Davison ${ }^{2}$
}

1 Institute of Terrestrial Ecology, Bush Estate, Penicuik, Midlothian EH:26 OQB, U.K., 2 Department of Biology, Ridley Building, The University, Newcastle upon Tyne, U.K., ${ }^{3}$ National Agency of Environmental Research, Institute of Air Pollution, Frederiksborgvej 399, D-4000, Roskilde, Denmark, and

4 Institute of Plant Ecology, University of Copenhagen, Ø Farimagsyade, 2D D/1353, Copenhagen, Denmark

\section{Introduction}

Much of the research investigating the effects of gaseous pollutants upon plants has been concerned with dose-response relationships, particularly during the period of fumigation or in between the periods of fumigation, in the summer. However, there is increasing evidence that these pollutants increase plant susceptibility to winter injury (Barnes and Davison, 1988; Brown et al., 1987). This is especially problematic for conifers, since they maintain needles and some metabolic activity throughout the winter. Indeed, there is increasing evidence that the forest decline documented for northeastern U.S.A. and Europe results from the interaction of various abiotic and biotic factors including air pollutants, frost and winter dessication (Brown et al., 1987; Barnes and Davison, 1988).

Anthropogenic ozone production primarily occurs during the summer when tem- peratures and light intensity are sufficiently high. Frost and winter dessication are therefore temporally separated from the periods of high ozone concentrations. Consequently, if ozone is to influence plant sensitivity to frost, it must exert a long-lasting effect. This paper briefly reports the results of an investigation into the long-lasting effects of ozone fumigation upon photosynthesis of Norway spruce. Measurements were conducted in the field 6-7 mo after the cessation of $2 \mathrm{yr}$ summer fumigation with ozone.

\section{Materials and Methods}

Four yr old seed-propagated trees of Norway spruce (Picea abies (L.) Karst) were exposed, in duplicate open top chambers at Riso National Laboratory, $30 \mathrm{krn}$ west of Copenhagen, Denmark, to either charcoal-filtered air or ambient air plus $50 \mathrm{ppb}$ ozone, from July to October 1986 and May to October, 1987. 
Table 1. Daily mean rates of photosynthesis $\left(\mu \mathrm{mol} \cdot \mathrm{m}^{-2} \cdot \mathrm{s}^{-1}\right)$ and total $\mathrm{CO}_{2}$ fixed per hour $\left(\mathrm{mmol} \cdot \mathrm{m}^{-2} \cdot \mathrm{h}^{-1}\right)$ for current and previous yr needles of Norway spruce seedlings that had received charcoal-filtered air (CF) or ozone-enriched air $\left(+\mathrm{O}_{3}\right)( \pm \mathrm{SE})$.

\begin{tabular}{|c|c|c|c|c|}
\hline \multirow[t]{2}{*}{ Treatment } & \multicolumn{2}{|c|}{ Daily mean photosynthetic rate } & \multicolumn{2}{|c|}{ Total $\mathrm{CO}_{2}$ fixed per hour } \\
\hline & $\begin{array}{l}\text { current yr } \\
\text { needles }\end{array}$ & $\begin{array}{l}\text { previous yr } \\
\text { needles }\end{array}$ & $\begin{array}{l}\text { current yr } \\
\text { needles }\end{array}$ & $\begin{array}{l}\text { previous yr } \\
\text { needles }\end{array}$ \\
\hline $\begin{array}{l}\mathrm{CF} \\
+\mathrm{O}_{3} \\
\% \text { difference }\end{array}$ & $\begin{array}{l}2.07 \pm 0.18 \\
2.61 \pm 0.18 \\
26\end{array}$ & $\begin{array}{l}1.61 \pm 0.14 \\
2.38 \pm 0.16 \\
48\end{array}$ & $\begin{array}{l}74 \pm 0.7 \\
98 \pm 0.5 \\
29\end{array}$ & $\begin{array}{l}54.5 \pm 0.5 \\
87 \pm 0.8 \\
50\end{array}$ \\
\hline
\end{tabular}

On November 25th, 1987 (42 d after the cessation of ozone fumigation), branches bearing 3 needle yr age classes were used for fluorescence analysis. A portable fluorometer (Richard Branker Research) attached to an oscilloscope with output to a digital plotter was used (Barnes and Davison, 1988). $F_{0}$ was readily determined due to the storage and display capabilities of the Gould 1425 digital storage oscilloscope, allowing millisecond resolution of the fluorescence curves. Fluorescence of wavelength $>710 \mathrm{~nm}$ (PSIl fluorescence) was measured. The Branker instrument provides illumination of approximately $4 \mu \mathrm{E} \cdot \mathrm{m}^{-2} \cdot \mathrm{s}^{-1} . F_{0}$ (non-variable fluorescence), $F_{v}$ (variable fluorescence) and $F_{r}$ (rate of rise of variable fluorescence) were determined as described elsewhere (Barnes and Davison, 1988). On May 8th, 1988 (207 d after the cessation of fumigation), rates of photosynthesis and transpiration were measured in the field using a portable ADC infrared gas analyzer and Parkinson leaf chamber. Current and previous yr needles were used. Twelve replicate branches per treatment were measured. Further details are given elsewhere (Eamus et al., 1989)

\section{Results}

Table I shows that for both current and previous yr needles, the mean rate of assimilation over the day was significantly $(P<1 \%)$ greater for ozone-fumigated trees than charcoal-filtered trees. A $26 \%$ and $48 \%$ increase for current and previous yr needles, respectively, was observed for
Table II. Long-lasting effects of $\mathrm{O}_{3}$ on the initial fluorescence level $\left(F_{0}\right)$, the yield of variable fluorescence $\left(F_{\mathrm{v}}\right)$ and the rate of rise in induced fluorescence $\left(F_{\mathrm{r}}\right)$ in 3 needle $\mathrm{yr}$ age classes of Norway spruce, $42 \mathrm{~d}$ after $\mathrm{O}_{3}$ fumigation was terminated.

\begin{tabular}{|c|c|c|}
\hline & \multicolumn{2}{|l|}{ Treatment ${ }^{\mathbf{a}}$} \\
\hline & $C F$ & $O_{3}$ \\
\hline $\begin{array}{l}F_{0}(\mathrm{mV}) \\
\text { current (1987) } \\
C+1(1986) \\
\mathrm{C}+2(1985)\end{array}$ & $\begin{array}{l}496 \pm 16.0 \\
489 \pm 21.9 \\
415 \pm 57.0\end{array}$ & $\begin{array}{l}531 \pm 30.5 \\
492 \pm 65.5 \\
390 \pm 52.5\end{array}$ \\
\hline $\begin{array}{l}F_{\mathrm{v}}(\mathrm{mV}) \\
\text { current }(1987) \\
\mathrm{C}+1(1986) \\
\mathrm{C}+2(1985)\end{array}$ & $\begin{array}{l}222 \pm 20.4 \\
171 \pm 26.5 \\
198 \pm 9.0\end{array}$ & $\begin{array}{l}184 \pm 18,5^{\star} \\
157 \pm 18.0^{\star} \\
160 \pm 31.9^{*}\end{array}$ \\
\hline $\begin{array}{l}F_{r}\left(m V 200 \mathrm{~ms}^{-1}\right) \\
\text { current }(1987) \\
\mathrm{C}+1(1986) \\
\mathrm{C}+2(1985)\end{array}$ & $\begin{array}{l}88 \pm 5.0 \\
62 \pm 6.5 \\
72 \pm 3.5\end{array}$ & $\begin{array}{l}66 \pm 3.5^{\star} \\
64 \pm 4.0 \\
57 \pm 10.0\end{array}$ \\
\hline
\end{tabular}

a $\mathrm{CF}$ : charcoal-filtered air; $\mathrm{O}_{3}$ : ozone-enriched air.

* Indicates significant differences $(P<0.05)$ between treatments. Values represent means \pm standard error.

ozone-filtered trees. Similarly, ozone fumigated trees fixed $29 \%$ (current) and $50 \%$ (previous) more $\mathrm{CO}_{2}$ per hour than charcoal-filtered trees. From Figs. 1 and 2, it can be seen that this was the result of: 1) the ozone-fumigated trees exhibiting a higher temperature response function than the charcoal-filtered trees, for both current 
a

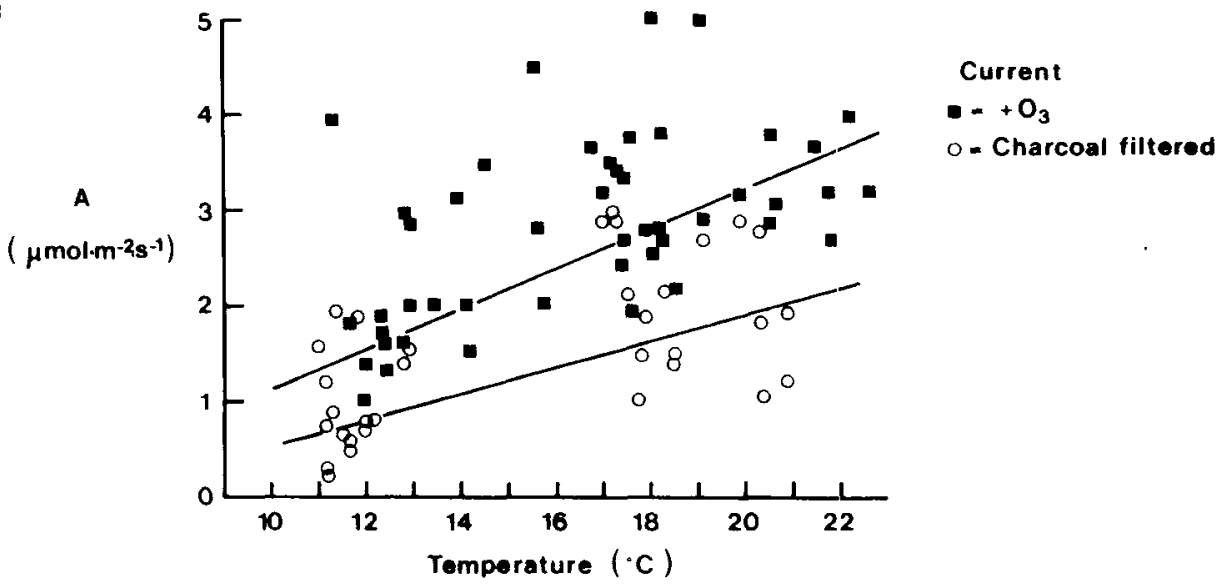

b

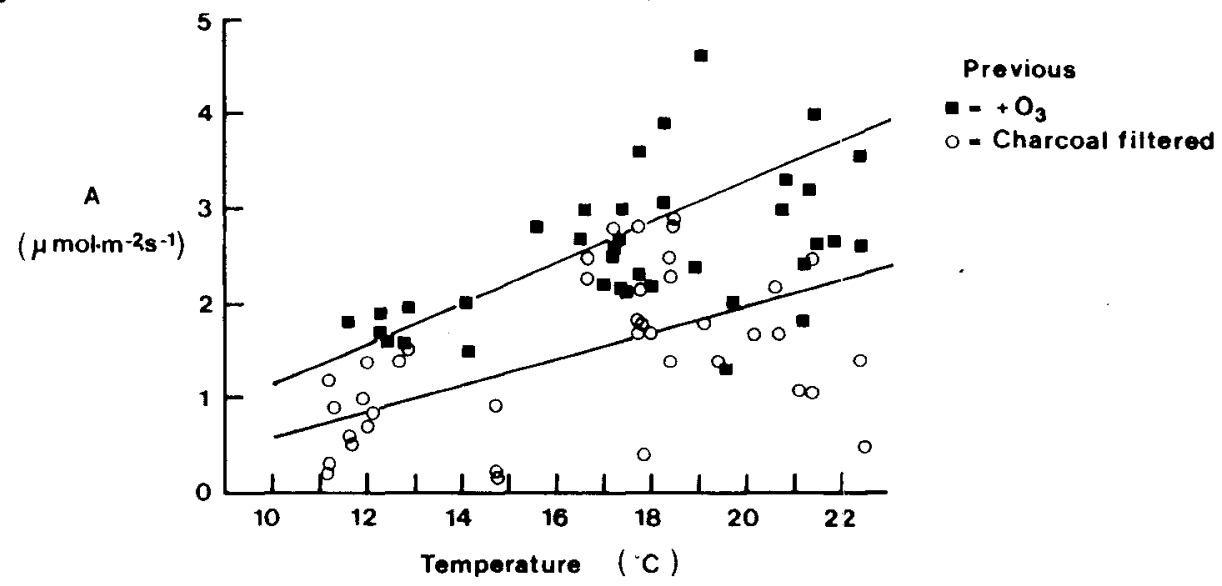

Fig. 1. Temperature response curve of assimilation for current (a) and previous (b) years' needles of 4 yr old Norway spruce, as measured in the field. The trees had received either charcoal-filtered air $(O)$ or ozone enriched $(\square)$ air.

and previous yr needles (Fig. 1), and 2) both a greater light saturated rate of assimilation and a higher apparent quantum yield than the charcoal-filtered trees (Fig. 2). The $r^{2}$ values for the apparent quantum yield regressions of the light response data (Fig. 2) and the temperature response of assimilation (Fig. 1) varied between 0.8 and 0.97 , indicating a satisfactory fit of the lines to the data sets.
Table II shows that there was no significant effect of the treatments upon $F_{0}$, for any of the $3 \mathrm{yr}$ classes of needles. However, the yield of variable fluorescence $\left(F_{v}\right)$ was significantly reduced in all $\mathrm{yr}$ classes, by ozone fumigation. The rate of rise of variable fluorescence $\left(F_{r}\right)$ was significantly decreased in current $y r$ needles only. There was no effect on $\mathrm{C}+1$ or $\mathrm{C}+2 \mathrm{yr}$ needles. 
a

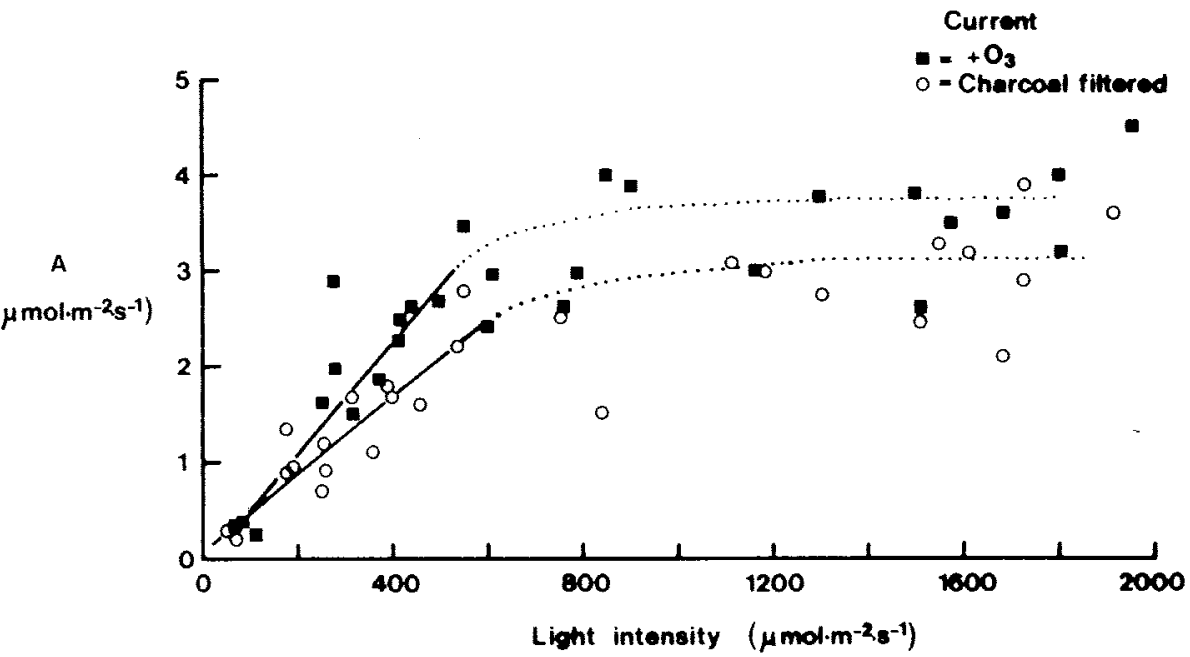

b

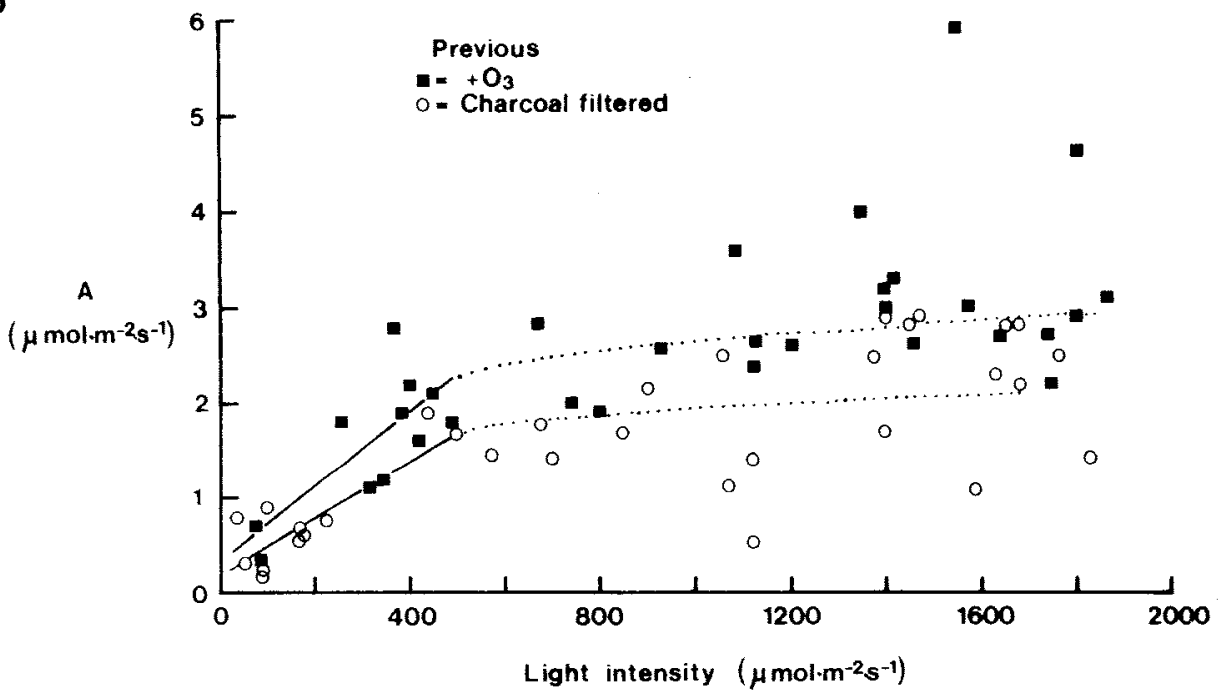

Fig. 2. Light response curve of assimilation for current (a) and previous (b) years' needles of 4 yr old Norway spruce trees, measured in the field. Linear regressions were fitted to all values of $A<500 \mu \mathrm{mol} \cdot \mathrm{m}^{-2} \cdot \mathrm{s}^{-1}$ PAR. Dotted curves were fitted by eye. The trees had received either charcoal filtered air $(O)$ or ozone enriched $(\square)$ air.

\section{Discussion and Conclusion}

Ozone fumigation resulted in significantly enhanced mean daily rates of assimilation in comparison to control plants, for current and previous yr needles (Table 1). This result is in contradiction with the data of large numbers of papers reporting that ozone fumigation causes decreased rates of assimilation (A). However, examples of ozone fumigation not affecting rates of $A$ 
(Chappelka and Chevone, 1988; Taylor et al., 1986) have been reported. The majority of these papers have been concerned with measurements of $A$ during the summer period coincidental with the time of ozone fumigation. The data presented in this paper show that ozone increased $A$ in the spring prior to budburst following a summer of ozone fumigation. Ozone decreases frost hardiness of Norway and Sitka spruce (Barnes and Davison, 1988; Lucas et al., 1988) particularly at the start and end of the winter period (i.e., during hardening and dehardening). It is suggested from the data of this study, that trees exposed to ozone during the summer were less hardy in May the following yr and thus were more active than control plants. From this it may be predicted that ozone-fumigated trees would have a higher temperature and light response curve for $A$ than control plants which were hardier and less metabolically active. This indeed was observed. Quantum efficiency, the rate of light-saturated $A$ and the temperature response of $A$ was greater in ozone-fumigated plants than controls (Figs. 1 and 2, Table I). It is concluded that ozone fumigation exerts a long-term effect upon Norway spruce via its influence upon the processes of hardening and subsequent dehardening. This makes the trees more frost sensitive, but also allows the ozone fumigated trees to take better advantage of warm, sunny days early in the season.

Table II shows that ozone fumigation significantly reduced the yield of variable fluorescence $\left(F_{\mathrm{v}}\right)$ for all yr classes, and also the rate of rise $\left(F_{r}\right)$ of induced fluorescence in the current yr needles. Such declines indicate that previous exposure to $\mathrm{O}_{3}$ caused long-term damage to the pho- tosynthetic processes (principally electron transport) which was not expressed as visible symptoms. Such latent damage has been associated with increased frost sensitivity (Barnes and Davison, 1988). These changes in fluorescence parameters were observed $42 \mathrm{~d}$ after cessation of ozone fumigation, indicating that these trees were more sensitive to early frost events as well as late frost events.

\section{References}

Barnes J.D. \& Davison A.W. (1988) The influence of ozone on the winter hardiness of Norway spruce. New Phytol. 108, 159-166

Brown K.A., Roberts T.M. \& Blank L.W. (1987) Interaction between ozone and cold sensitivity in Norway spruce: a factor contributing to the forest decline in central Europe. New Phytol. 105, 149-155

Chappelka A.H., Chevone B.I. \& Seiler J.R. (1988) Growth and physiological responses of yellow poplar seedlings exposed to ozone and simulated acidic rain. Environ. Pollut. 49, 1-18

Eamus D. \& Fowler D. (1989) Photosynthetic and stomatal conductance responses of red spruce seedlings to acid mist. Plant Cell Environ. in press

Eamus D., Barnes J.D., Mortensen L., Ro-Poulsen H. \& Davison A.W. (1989) Persistent effects of summer ozone fumigation on $\mathrm{CO}_{2}$ assimilation and stomatal conductance in Norway spruce. Environ. Pollut. in press

Lucas P.W., Cottam D.A., Sheppard L.J. \& Francis B.J. (1988) Growth responses and delayed winter hardening in Sitka spruce following summer exposure to ozone. New Phytol. 108, 495-504

Taylor G.E., Norlsy R.J., McLaughlin S.B., Johnson A.H. \& Turrier R.S. (1986) Carbon dioxide assimilation and growth of red spruce seedlings in response to ozone and precipitation chemistry and soil type. Oecologia (Berlin) 70, 163-171 